\title{
Behind the Great Recession: Job Search and Housing Decisions*
}

\author{
Sílvio Rendon Núria Quella \\ Stony Brook University
}

November 2013

\begin{abstract}
In this paper we analyze a mechanism that is particularly relevant to the workings of the Great Recession: we explain how easier home financing and higher homeownership rates increase unemployment rates. To this purpose we build a model of job search with liquid wealth accumulation and consumption of housing, that can be rented, bought on credit, or sold. In our model, more relaxed house credit conditions increase workers' reservation wages, making them more selective in their job search. More selective job searches deteriorate employment transitions: job finding and job-to-job transitions rates decline while job loss rates increase, causing the overall unemployment rate to rise. We estimate this model structurally using NLSY data from 1978 until 2005. We find that more relaxed housing lending conditions, particularly lower downpayment requirements, increase unemployment rates by 6 percent points. We also find that declining labor demand decreases homeownership rates by 14 percent points.
\end{abstract}

Keywords: Job Search, Housing, Savings, Structural Estimation.

JEL Classification: J64, E21, E24, R21.

\footnotetext{
*Our emails: rensilvio@gmail.com,nq2130@columbia.edu. We thank participants at the Midwest Macroeconomics Conference 2010 in East Lansing, the Eastern Economic Association Annual Meetings in 2011 in New York City, the Anual Meeting of the Society for Economic Dynamics of 2011 in Ghent, the NYU Alumni Conference in 2013, and seminar participants at Fordham University, Barnard College, and Columbia University (SIPA).
} 


\section{Introduction}

Do the housing decisions of individuals influence their labor market outcomes? How about the home financing conditions they face, do they have an impact on their job situation? Empirically, homeownership has been associated with higher unemployment rates, however, there has been no theory that would explain why or how. In this article we present a model in which reservation wages are the underlying mechanism through which more relaxed credit conditions and higher homeownership rates cause higher unemployment rates.

Our theoretical framework is a utility-maximizing job search model, extended to allow for consumption of a durable: housing. The desired amount of housing units can be bought on credit, sold or rented. This framework allows us to evaluate the dynamics of homeownership, unemployment, employment transitions, and wages under varying home lending conditions. We find that more relaxed housing lending conditions increase workers' reservation wages, making them more selective in their job search. This, in turn, causes their employment transitions to deteriorate: job finding and job-to-job transitions rates decline, while job loss rates increase, so that the overall unemployment rate increases by 6 percent points. We also find that worsening labor market conditions decrease homeownership rates by 14 percent points.

Several empirical studies find a positive relation between homeownership and unemployment rates. Oswald $(1997,2013)$ was the first to show this connection based upon analysis of time series and cross-section data for OECD countries and for regions within selected OECD countries. He finds that countries and regions with ten percent higher homeownership rates have two percent higher unemployment rates. So far, arguments supporting or refuting this finding consist of empirical tests. Flatau, Forbes, Hendershott and Wood (2003) provide a summary of the empirical results on the relationship between unemployment and homeownership. In particular, Green and Hendershott (2001) replicate Oswald's results for the U.S. states and by age group within states. And Bover, Muellbauer, and Murphy (1989) empirical analysis on UK data find cross-sectional evidence on the effects of house tenure structure on mobility, that is, lagged values of regional differentials in the ratio of house prices to earnings play an important role in both the wage and the unemployment/vacancies equations. In addition, lagged values of average house prices have a significant 'cost-of-living' effect on wages. More recently, Mian and Sufi (2011) estimates show that household leverage growth explains a large fraction of residential investment, unemployment, 
and durable consumption patterns during the Great Recession.

The present paper is the first to explain decisions on home tenure in close connection with the process of job search. ${ }^{1}$ In our model individuals maximize lifetime utility while they search for jobs, accumulate liquid wealth, ${ }^{2}$ and consider buying a house of the desired size, the price of which will fluctuate. Previous dynamic models have already considered the housing choice, ${ }^{3}$ however, in all these frameworks the individual's income process is exogenous. Here individuals decide on housing, savings, and job search, so that there is an explicit feed-back effect between the housing market and the individuals' income process.

This analysis is particularly relevant to understanding the Great Recession of 2007-09, in which the housing bubble burst amidst lax credit conditions (housing and subprime crises), and was followed by unemployment, job insecurity, and low growth in incomes, which further deteriorated the housing market. ${ }^{4}$ The workings of this second mechanism or how deteriorating labor market conditions (and lending to those who lose their jobs) negatively impact housing are quite clear. However, the first initial mechanism, or how lax housing credit conditions (low or no downpayment, smaller initial mortgage payments) increase unemployment rates by increasing reservation wages, is far more interesting and much less understood. This paper aims to shed light on both.

To this purpose we give explicit consideration to the connection between the financial and the real economy. Most economic analyses regarding this connection focus on the impact of financial variables on firms' real decisions. Here we focus on the homeownership and employment decisions of individuals that search for jobs while facing changing housing credit conditions, which affect their employment situation and income stream. It is only in the absence of frictions for buying and selling property that homeownership status has no impact on an individual's employment situation

\footnotetext{
${ }^{1}$ Laufer (2008) is the only previous model that integrates job search and housing decisions.

${ }^{2}$ The job search model here is set up along the lines of Mortensen (1977) and Burdett and Mortensen (1998) and includes wealth accumulation as in Danforth (1979), Acemoglu and Shimer (1999), Costain (1999), Rendon (2006), Lentz (2009), and Lise (2013).

${ }^{3}$ Notably Gervais (2002), Sanchez (2007), Yang (2009), Díaz and Luengo-Prado (2010), Chambers, Garriga, and Schlagenhauf (2011), Fisher and Gervais (2011), Sommer, Sullivan, and Verbrugge (2013), Iacoviello and Pavan (2013).

${ }^{4}$ Arguably, lax downpayment requirements and low initial payments in mortgages have played an important role in the current crisis. Haurin, Hendershott, and Wacther (1997) find ownership to be quite sensitive to potential earnings, the cost of owning relative to renting, and especially borrowing constraints. Chambers, Garriga, and Schlagenhauf (2009) show in a quantitative exercise that innovations resulting in a lowering of the downpayment requirement can help explain the riseand fall-in homeownership since 1994.
} 
and income stream. Therefore, in our framework lifetime income is endogenous and responsive to financial conditions.

To estimate the behavioral parameters of the theoretical model we input its policy rules in a simulated method of moments estimation. This way the model's simulations match the observed patterns of wealth accumulation, home tenure, wage growth, and job turnover in the U.S. The data for this estimation come from the National Longitudinal Survey of Youth (NLSY), which provides us with a detailed work history of individuals from 1978 until 2010, including their employment transitions, wages, and several types of wealth, including residential wealth. The model fits the data reasonably well.

Once the behavioral parameters are recovered, we evaluate the dynamics of unemployment, employment transitions, wealth accumulation, and homeownership under two counter-factual scenarios: (i) more relaxed conditions for housing credit, and (ii) deterioration of labor market demand. We accomplish these scenarios by modifying the underlying parameters that we estimated previously. The first regime change aims to assess the effect of relaxed lending conditions for housing in the early 2000s, whereas the second regime change is geared toward assessing the decline in hiring by firms once the crisis broke up in the late 2000s.

The first regime change reveals that more generous credit conditions to buy a house, in particular lower downpayment requirements, increase unemployment substantially, by up to 6 percentage points. The second regime change shows that falling labor market demand, in particular lower arrival rates, decreases homeownership by up to 14 percentage points. We also evaluate the government policy of increasing unemployment transfers, as discussed recently by Rothstein (2011) and Hagedorn et al. (2013), and we find that there is an additional 4 percentage point impact on the unemployment rate.

The remainder of the article is organized as follows. The next section explains the model and characterizes the optimal solution. Section 3 describes the data used in the estimation and documents their basic trends. Section 4 details the estimation procedure, in particular, the criterion function of the simulated method of moments estimation. Section 5 presents the results of the estimation, the behavioral parameters and an assessment of how well the model fits the data. Section 6 performs the three policy experiments mentioned above. The main conclusions of this article are summarized in Section 7. 


\section{Model}

Individuals maximize their expected lifetime utility by choosing their home size and home tenure status (owning or renting the house in which they live), the level of consumption of non durables, and acceptable wage offers.

Agents finish their schooling and immediately enter the labor market in quarter 1. That is, agents are active, employed or unemployed, during $t \in\{1, \ldots, T\}$ quarters, then retire and live for $t \in\left\{T+1, \ldots, T_{F}\right\}$ additional quarters. There are no bequests, so agents die in period $T_{F}$ without assets.

Specifically, in quarter 1 agents are 18, then stay in the labor market for a total of 47 years until age 65 , when they retire; that is, agents are active for $T=188$ quarters. Once agents retire, they live an additional 16 years (or 64 quarters) until the age of 81; that is, agents live for a maximum of $T_{F}=252$ quarters.

In each period $t$ individuals derive utility from consumption of non-durables, $C_{t}$, and from consuming the services of a house of size $H_{t} \in[\underline{H}, \bar{H}]$, which they can own or rent, so that their period-by-period utility function is $U(C, H)$. Renters can adjust the level of housing services they consume without cost as long as they remain renters. But first-time buyers and owners that change the size of their house must bear a price-dependent adjustment cost of the form

$$
c\left(\chi_{t-1} H_{t-1}, \chi_{t} H_{t}, p_{t}\right)=p_{t}\left(\chi_{t} H_{t}-\chi_{t-1} H_{t-1}\right)+a p_{t}\left|\chi_{t} H_{t}-\chi_{t-1} H_{t-1}\right|,
$$

where the value of $\chi$ indicates whether a house is owned $(\chi=1)$ or rented $(\chi=0)$ in a particular period; $p_{t}$ is the price per house unit in period $t$; and $a$ is equivalent to a fee per unit of variation in house size. ${ }^{5}$ When there is no variation in house size $c(\cdot)=0$. There is no house depreciation and no house maintenance spending. The house price follows a Markov process $P\left(p^{\prime} \mid p\right)$, parameterized as an $\operatorname{AR}(1)$ process: $\ln p_{t+1} \sim N\left(\mu_{p}+\phi \ln p_{t}, \sigma_{p}^{2}\right)$, where $p_{t} \in[\underline{p}, \bar{p}], 0<\underline{p}<\bar{p}<+\infty$. Rental payments are $r_{h} H_{t}$, where $r_{h}$ is the rent per house unit.

Agents can buy or sell a house throughout their lifetime, but they can only experience employment transitions during their active period. Unemployed agents receive transfers $b$, which include non-labor income, like family transfers, plus unemployment compensation net of out-of-pocket search costs. Retired agents receive a pension $b_{R}$. These transfers allow agents to rent at least the smallest size house (No-homelessness

\footnotetext{
${ }^{5}$ This cost is equivalent to requiring the house be sold each time there is a variation in house size, as in Flavin and Nakagawa (2008).
} 
condition):

$$
b, b_{R} \geq r_{h} \underline{H} .
$$

All agents enter active life as unemployed and with an initial stock of liquid wealth $A_{0}$. Agents have a subjective discount factor $\beta \in(0,1)$, can save at rate of return $r$, and can borrow up to a limit $B_{t+1}$ at that same rate. This limit on borrowing is determined by the liquidation value of an owned house used as collateral: ${ }^{6}$

$$
B_{t+1}\left(\chi_{t} H_{t}\right) \equiv-(1-d) \underline{p} \chi_{t} H_{t}
$$

where $d$ is the downpayment rate. This limit ensures lenders will always be repaid. ${ }^{7}$

Unemployed agents receive a wage offer $x$ with probability $\lambda_{t}^{u}$, drawn from a wage offer distribution $F(\cdot),(x \in(\underline{w}, \bar{w}), 0<\underline{w}<\bar{w}<\infty)$. They become employed if they receive and accept a wage offer; otherwise they remain unemployed. Employed agents are laid off with probability $\theta_{t}$ and with probability $\pi_{t}$ they receive a wage offer drawn from the same distribution $F(\cdot)$. They change employer when they receive an offer and accept it; they continue working for the same employer when they are not laid off, receive an offer that they do not accept or no offer at all, and the current job is preferable to unemployment; they can always quit to become unemployed. Arrival rates, $\lambda_{t}$, layoff rates $\theta_{t}$, and wages $w_{t}(\omega)$ are age-specific. The evolution by age of these labor market parameters captures the accumulation of human capital over time.

The present discounted utility of a retired agent of age $t=T+1, \ldots, T_{F}$, with liquid wealth holdings $A_{t}$, who may own a house of size $H_{t-1}$ and house price $p_{t}$ is

$$
\begin{aligned}
& V_{t}^{R}\left(A_{t}, \chi_{t-1} H_{t-1}, p_{t}\right)= \\
& \quad \max _{A_{t+1}^{R} \geq 0, \chi_{t}, H_{t}}\left\{U\left(A_{t}+b_{R}-c\left(\chi_{t-1} H_{t-1}, \chi_{t} H_{t}, p_{t}\right)-\left(1-\chi_{t}\right) r_{h} H_{t}-\frac{A_{t+1}}{1+r}, H_{t}\right)\right. \\
& \left.+\beta \int V_{t+1}^{R}\left(A_{t+1}, \chi_{t} H_{t}, p_{t+1}\right) d P\left(p_{t+1} \mid p_{t}\right)\right\},
\end{aligned}
$$

where, in the absence of bequest motives, $A_{T_{F}+1}=0$. The solution to this problem is contained in the wealth accumulation rule $A_{t+1}^{R}\left(A_{t}, H_{t-1}, p_{t}\right)$ and the housing decision rules $\chi_{t}^{R}\left(A_{t}, H_{t-1}, p_{t}\right)$ and $H_{t}^{R}\left(A_{t}, H_{t-1}, p_{t}\right)$.

\footnotetext{
${ }^{6}$ Banks do not lend to retirees: retired agents cannot borrow at all, not on account of their pension, nor can they have any kind of debt on their house, were they to own one.

${ }^{7} \mathrm{~A}$ fraction of future secure no-homelessness income could also be included in the borrowing limit: $B_{t+1}=-s \sum_{j=t}^{T} \frac{b-r_{h} \bar{p} H}{(1+r)^{j}}-(1-d) \underline{p} \chi_{t} H_{t}$. We previously conducted estimations of this specification with the result that $s$ was very close to zero.
} 
Active agents maximize their expected lifetime utility by choosing their current home tenure status, level of consumption, and acceptable wage offers, conditional on their wealth, and previous home tenure status, wages and employment situation. Expected lifetime utility $V_{t}^{u}$ when unemployed at age $t(=1, \ldots, T)$ is defined as

$$
\begin{aligned}
& V_{t}^{u}\left(A_{t}, \chi_{t-1} H_{t-1}, p_{t}\right)= \\
& \max _{A_{t+1}^{R} \geq B_{t+1}, \chi_{t}, H_{t}}\left\{U\left(A_{t}+b-c\left(\chi_{t-1} H_{t-1}, \chi_{t} H_{t}, p_{t}\right)-\left(1-\chi_{t}\right) r_{h} H_{t}-\frac{A_{t+1}}{1+r}, H_{t}\right)\right. \\
& +\beta\left[\lambda_{t+1} \iint \max \left[V_{t+1}^{e}\left(A_{t+1}, x, \chi_{t} H_{t}, p_{t+1}\right), V_{t+1}^{u}\left(A_{t+1}, \chi_{t} H_{t}, p_{t+1}\right)\right] d F(x) d P\left(p_{t+1} \mid p_{t}\right)\right. \\
& \left.\left.+\left(1-\lambda_{t+1}\right) \int V_{t+1}^{u}\left(A_{t+1}, \chi_{t} H_{t}, p_{t+1}\right) d P\left(p_{t+1} \mid p_{t}\right)\right]\right\} .
\end{aligned}
$$

Expected lifetime utility $V_{t}^{e}$ at age $t=1, \ldots, T$ for an individual that is employed, has wealth holdings $A_{t}$, base wage $\omega$, and who may own a house of size $H_{t-1}$ at unit house price $p_{t}$ is

$$
\begin{aligned}
& V_{t}^{e}\left(A_{t}, \omega, \chi_{t-1} H_{t-1}, p_{t}\right)= \\
& \max _{A_{t+1}^{R} \geq B_{t+1}, \chi_{t}, H_{t}}\left\{U\left(A_{t}+w_{t}(\omega)-c\left(\chi_{t-1} H_{t-1}, \chi_{t} H_{t}, p_{t}\right)-\left(1-\chi_{t}\right) r_{h} H_{t}-\frac{A_{t+1}}{1+r}, H_{t}\right)\right. \\
& +\beta\left(\left\{\left(1-\theta_{t+1}\right)\right.\right. \\
& {\left[\pi_{t+1} \iint \max \left[V_{t+1}^{e}\left(A_{t+1}, \max (x, \omega), \chi_{t} H_{t}, p_{t+1}\right), V_{t+1}^{u}\left(A_{t+1}, \chi_{t} H_{t}, p_{t+1}\right)\right] d F(x) d P\left(p_{t+1} \mid p_{t}\right)\right.} \\
& \left.\left.\left.+\left(1-\pi_{t+1}\right) \int \max \left[V_{t+1}^{e}\left(A_{t+1}, \omega, \chi_{t} H_{t}, p_{t+1}\right), V_{t+1}^{u}\left(A_{t+1}, \chi_{t} H_{t}, p_{t+1}\right)\right]\right) d P\left(p_{t+1} \mid p_{t}\right)\right]\right\} \\
& +\left\{\theta _ { t + 1 } \left[\pi_{t+1} \iint \max \left[V_{t+1}^{e}\left(A_{t+1}, x, \chi_{t} H_{t}, p_{t+1}\right), V_{t+1}^{u}\left(A_{t+1}, \chi_{t} H_{t}, p_{t+1}\right)\right] d F(x) d P\left(p_{t+1} \mid p_{t}\right)\right.\right. \\
& \left.\left.\left.\left.+\left(1-\pi_{t+1}\right) \int V_{t+1}^{u}\left(A_{t+1}, \chi_{t} H_{t}, p_{t+1}\right)\right) d P\left(p_{t+1} \mid p_{t}\right)\right]\right\}\right) .
\end{aligned}
$$

Active agents solve a dynamic problem with a finite horizon $T$ and a 'salvage value' which is the present discounted utility at retirement: $V_{t}^{u}\left(A_{t}, \chi_{t-1} H_{t-1}, p_{t}\right)=$ $V_{t}^{e}\left(A_{t}, \omega, \chi_{t-1} H_{t-1}, p_{t}\right)=V_{t}^{R}\left(A_{t}, \chi_{t-1} H_{t-1}, p_{t}\right)$, at $t=T+1$.

The solution to this problem is contained in six policy rules: $A_{t+1}^{u}\left(A_{t}, \chi_{t-1} H_{t-1}, p_{t}\right)$, $A_{t+1}^{e}\left(A_{t}, \omega, \chi_{t-1} H_{t-1}, p_{t}\right), \chi_{t}^{u}\left(A_{t}, \chi_{t-1} H_{t-1}, p_{t}\right), \chi_{t}^{e}\left(A_{t}, \omega, \chi_{t-1} H_{t-1}, p_{t}\right), H_{t}^{u}\left(A_{t}, \chi_{t-1} H_{t-1}, p_{t}\right)$, and $H_{t}^{e}\left(A_{t}, \omega, \chi_{t-1} H_{t-1}, p_{t}\right)$. That is, wealth accumulation and house consumption depend on liquid wealth, employment status, wages if employed, and also on homeownership status and house prices. For this problem there exists a reservation wage 
that indicates the lowest acceptable wage offer:

$$
\omega_{t}^{*}\left(A_{t}, \chi_{t-1} H_{t-1}, p_{t}\right) \equiv\left\{\omega \mid V_{t}^{u}\left(A_{t}, \chi_{t-1} H_{t-1}, p_{t}\right)=V_{t}^{e}\left(A_{t}, \omega, \chi_{t-1} H_{t-1}, p_{t}\right)\right\} .
$$

The reservation wage depends on holdings of liquid assets, homeownership status and house consumption, and house prices. This model thus creates an explicit connection between wealth accumulation, homeownership, house prices, and job transitions.

Proposition 1 If the adjustment fee is zero $(a=0)$ and the borrowing limit is independent of homeownership status, $B_{t+1}\left(\chi_{t} H_{t}\right)=c, c \in \mathbb{R}$, lifetime value functions will be unaffected by the liquidity structure of wealth and will only be determined by the amount of total wealth $Z_{t}=A_{t}+p_{t} H_{t-1}$ :

$$
\begin{aligned}
V_{t}^{e}\left(A_{t}, \omega, H_{t-1}, p_{t}\right) & =V_{t}^{e}\left(\alpha Z_{t}, \omega,(1-\alpha) \frac{Z_{t}}{p_{t}}, p_{t}\right), \\
V_{t}^{u}\left(A_{t}, H_{t-1}, p_{t}\right) & =V_{t}^{u}\left(\alpha Z_{t},(1-\alpha) \frac{Z_{t}}{p_{t}}, p_{t}\right),
\end{aligned}
$$

where $\alpha \in[0,1]$, for all $A_{t}, H_{t-1}, p_{t}$.

Proof: In Appendix A1.

If there is no adjustment fee and the borrowing limit is not house status-dependent, objective functions will be unaffected by whether wealth is held in liquid assets or illiquid property: owning a house of size $H_{t-1}$ has the same effect on lifetime utility as holding its value $p_{t} H_{t-1}$ in liquid assets. In other words, in the absence of adjustment fees and of any dependence of the borrowing limit on the housing status, how liquid her wealth is becomes irrelevant for an agent wishing to maximize her lifetime utility; only her total wealth is relevant. This property is reflected in the reservation wage.

Corollary 1 As value functions are determined just by total wealth, so are reservation wages. If adjustment fees are zero $(a=0)$ and the borrowing limit does not depend on homeownership status, $B_{t+1}\left(\chi_{t} H_{t}\right)=c, c \in \mathbb{R}$, the reservation wage will be the same whether the individual owns a house of size $H_{t-1}$ or whether she holds $p_{t} H_{t-1}$ in liquid assets:

$$
\omega^{*}\left(A_{t}, H_{t-1}, p_{t}\right)=\omega^{*}\left(\alpha Z_{t},(1-\alpha) \frac{Z_{t}}{p_{t}}, p_{t}\right) .
$$


In the absence of adjustment fees and of house dependent borrowing limits, the reservation wage does not depend on the liquidity structure of wealth, but on its total size. Notice that a special case of $B_{t+1}\left(\chi_{t} H_{t}\right)=c$ is that $c=0$, that is, $d=1$, which implies that liquid wealth cannot be negative. In this case, there is no borrowing at all, $B_{t+1}\left(\chi_{t} H_{t}\right)=0$. At the other extreme, $c$ may be a very large negative number, which is equivalent to removing the borrowing constraint.

Because there are no closed-form solutions to this model, we assume specific functional forms. Our utility function is a Cobb-Douglas embedded into a constant relative risk aversion (CRRA) utility function:

$$
U(C, H)=\frac{\left(C^{\rho} H^{1-\rho}\right)^{1-\gamma}-1}{1-\gamma},
$$

where $\gamma$ is the coefficient of relative risk aversion, and $\rho$ represents the share of consumption of non-durables.

The base wage offer distribution is a truncated lognormal $F(x): \ln \omega \sim N\left(\mu, \sigma^{2} \mid \underline{\omega}, \bar{\omega}\right) ; 0<$ $\underline{\omega}<\bar{\omega}<\infty$; and age-dependent arrival and layoff rates are logistic: $q_{t}^{k}=\frac{\exp \left(\alpha_{q}^{0}+\alpha_{q} t\right)}{1+\exp \left(\alpha_{q}^{0}+\alpha_{q} t\right)}$, where $q=\{\lambda, \pi, \theta\}$. Finally, the wage growth function has the form $w_{t}(\omega)=\omega \exp \left(\alpha_{1} t+\alpha_{2} t^{2}\right)$.

Approximation to the policy rules and value functions is done numerically. We allow wealth and wages to be continuous while we discretize house size and house prices. Accordingly we use the Euler equation and an interpolation algorithm to solve for wealth next period and a numerical maximization to solve for housing. We integrate the value functions for wages exploiting an interpolation technique while we integrate over prices by using a weighted summation. The dynamic problem is solved backward, starting with retirement and ending in period one.

The policy rules are illustrated in Figure 1, which shows the reservation wage and the house size bought as a function of liquid wealth. ${ }^{8}$ Both are increasing in wealth, that is, wealthier workers are more selective in their job search and buy larger houses. Because house sizes are discretized, they increase in jumps as a function of liquid wealth. And these jumps are associated with some drops in the reservation wage, which nevertheless exhibits an increasing tendency as a function of wealth.

Figure 2 shows the reservation wage as a function of wealth by house size. When liquid wealth is held constant, reservation wages are clearly higher the larger the house owned. This implies that homeowners are more selective than renters, if they

\footnotetext{
${ }^{8}$ For the characterization of the model in these policy rules and in the following sensitivity analysis, we use the estimated parameters of Table 5 .
} 
hold the same level of liquid wealth.

Figure 3 shows the effect of homeownership on the reservation wage when total wealth is held constant. Accordingly, larger liquid wealth holdings are associated with less residential wealth, as the figure shows. As stated in Proposition 1, when adjustment fees are zero and downpayment rates are one, the reservation wage is unaffected by the mix of wealth. In the simulated example, adjustment fees are positive and downpayment rates are less than one. As the graph shows for several total wealth levels, the reservation wage is affected by the mix of wealth. If the agent owns a large house but is indebted (holds negative liquid wealth), he is not as selective in his job search and his reservation wage is relatively low. However, if his liquid wealth is large and consequently he has a smaller house, his reservation wage is relatively larger. For large positive liquid wealth the reservation wage is slightly decreasing in liquid wealth, and hence increasing in the size of the house. Thus, reservation wages in general are affected not just by the amount of total wealth, but also by its composition. The graph suggests that reservation wages are at their highest at some balanced combination of liquid and residential wealth, and at their lowest at the extremes, when only one type of wealth is held, particularly when liquid wealth is negative.

We also perform a sensitivity analysis in which we change the baseline value of each parameter in the model, one at a time, and measure the resulting effects on selected statistics such as the homeownership rate, holdings of liquid wealth by homeownership status, wages, the unemployment rate, and employment transitions (from unemployment to being employed, from employment to becoming unemployed, and from one job to another one). We report these results in Table 1.

[Table 1 here]

Our baseline scenario refers to variable values 20 years (or 80 quarters) after individuals started their careers, assuming that all of them started off unemployed with no house and zero liquid wealth. The baseline homeownership rate is $58.5 \%$. These homeowners hold almost $\$ 10,000$ less in liquid assets than renters and, moreover, are $\$ 324$ in debt. The overall unemployment rate is almost $32 \%$, and the percentage of unemployed individuals that find a job is about $22 \%$. Around $10 \%$ of the employed lose their job, and only $4.4 \%$ transition directly to a new job.

Clearly, the parameter that has most influence on home tenure decisions is the downpayment requirement $d$; increasing $d$ in 0.1 reduces the percentage of homeown- 
ers by almost 16 percent points. This change also acts as a disincentive to save and thus elicits the largest decrease in the savings of renters and a smaller decline in the liquid assets of owners. This change in the housing market has an important impact in the labor market: it decreases wages and unemployment substantially, while improving job transitions (decrease in transitions from employment to unemployment, and increase in exits from unemployment).

Increases in the adjustment fee $a$, in the mean price of house units $\mu_{p}$, and in the rent $r_{h}$ work in the same direction for possibly the same reason. Renters may become discouraged and reduce savings earmarked for future home purchases; owners may stop considering a potential move to a larger house and also reduce savings. These changes discourage savings and reduce homeownership while decreasing the reservation wage, so that both wages and unemployment rates decrease. An increase in price variability of a housing unit $\sigma_{p}$ has the same effect on job variables but whereas it decreases wealth of renters, it increases liquid wealth of owners and homeownership. Therefore an increase in price variability acts as a disincentive to save before buying a house, but once the individual owns a house he may find it convenient to hold more liquid wealth. On the contrary, an increase in the persistence parameter $\phi$ has the opposite effect: it increases wealth holdings both for renters and owners as well as homeownership, while it has a small positive impact on wages, on the rate of unemployment, and on transitions from employment to unemployment, so that it would appear it allows individuals to be more selective on their job decisions. In general, as would be expected, homeowners holdings of liquid wealth are relatively more sensitive to changes in any of the housing parameters than renters' liquid wealth. It is also worth noticing that homeownership rates are more responsive to variations in credit market conditions (that is, in $d$ and $a$ ) and in rent than to changes in the housing market parameters $\left(\phi, \mu_{p}\right.$, and $\left.\sigma_{p}\right)$.

An increase in the share of income spent on non durables, $\rho$, prompts a decrease in homeownership rates of almost 3 percent points, and a decrease in the liquid wealth of owners and, especially, renters. Owners increase debt, possibly because owning a house has a positive wealth effect (absent in renting) that allows homeowners to borrow on account of their house. Renters just spend (i.e. decrease the positive value of) their wealth. This change decreases reservation wages, so that accepted wages and the unemployment rate decline. An increase in the coefficient of risk aversion, $\gamma$, decreases liquid wealth holdings of both renters and owners, while it also decreases wages and unemployment rates. Intuitively, higher risk aversion decreases 
the incentive to save to buy a house, which is subject to stochastic price changes. Thus liquid wealth holdings of both renters and owners go down, particularly of renters who are saving to buy a house. Besides this wealth effect, an increase in risk aversion also causes a fall in reservation wages conditional on liquid wealth.

In the lower half of Table 1 we can see the impact on the same model variables of changes of labor market parameters: unemployment transfers, the arrival rates when unemployed and employed (and their respective growth rates), the layoff rate (and its growth rate), the mean logwage (and its linear growth rate), and its standard deviation.

An increase in unemployment transfers, $b$, raises the percentage of homeowners, because it increases the reservation wage and encourages savings, regardless of whether the worker is a renter or a homeowner. Accordingly, it increases wages, the unemployment rate, and decreases transitions from unemployment to employment.

However, the single largest impact on homeownership rates comes from higher arrival rates when unemployed, $\lambda$ : a 0.1 increase in $\lambda$ increases the percentage of homeowners by almost 9 percentage points. It also generates large increases in savings of both renters and homeowners, as they go from receiving unemployment transfers to receiving a wage that is, most probably, higher. As demand for labor increases, so do wages, whereas the unemployment rate decreases and transitions from unemployment to employment improve.

When the arrival rate from employment, $\pi$, increases homeownership and savings also increase, as workers are possibly transitioning to better suited, better paid jobs. On the contrary, when the layoff rate, $\theta$, increases homeownership declines, as do savings of both renters and owners. Unemployed workers must, at least partly, finance their unemployment spells, and homeowners must certainly go on paying mortgages. Since labor demand decreases, wages also decrease and the rate of unemployment increases. As would be expected, transitions from employment to unemployment increase, but so do transitions to employment (workers become less selective with their job search). Increased growth of base arrival rates produces similar effects in all main statistics.

An increase in the mean wage, $\mu$, increases homeownership and savings, and has a very small positive effect on the unemployment rate and hardly any on job transitions. An increase of its linear growth rate, though, has a remarkable positive impact on savings.

The most interesting effects analyzed here are the 'cross-effects,' that is, effects 
of housing market parameters on labor market observables, and of labor market parameters on housing market observables. We have shown so far that both of these effects are fairly important in the model. In the next sections, we will confront this model to actual data.

\section{Data}

We use data from the National Longitudinal Survey of Labor Market Experience Youth Cohort (NLSY), a national stratified sample of 12,686 individuals who were between 14 and 21 years of age in January 1979, and who have been interviewed annually from 1979 until 2010. This dataset contains information on personal characteristics of the individual, household composition, educational status and attainment, military experience, labor market activity and transitions, detailed week-by-week work history, income and several forms of wealth, including residential property.

Total wealth is the net market value of the sum of residential wealth and liquid wealth. Residential wealth is the market value of the house if it were sold at the time of the interview. Liquid wealth consists of business assets, financial assets, vehicles, and other assets (such as jewelry or furniture), all net of debts, minus all debts on residential property. Annual data on residential wealth and the various forms of liquid wealth are available from year 1985 onwards; this information is assigned to the calendar quarter in which the interview took place. ${ }^{9}$

Out of the total number of respondents we select a sample which is more likely to conform to our theoretical model: white males born after December 31, 1960, without military experience, that finished High School and have at most one year of college, and for whom wealth and housing data are available. We are left with a sample of 268 individuals, who satisfied all the selection criteria. In this final sample each individual has up to 132 quarterly observations for wealth, housing, wages, employment status and employer. Appendix A2 provides further explanations of these variables.

[Table 2 here]

\footnotetext{
${ }^{9}$ All assets are defined by the NLSY as the amount the respondent would reasonably expect someone to pay if the particular asset were sold in its current condition at any point in time. We use the CPI reported by the BLS in ftp://ftp.bls.gov/pub/special.requests/cpi/cpiai.txt to convert market value to $1982-4$ dollars.
} 
Table 2 presents summary statistics for the variables used in this paper. On average $37 \%$ of the individuals in the sample are homeowners, with a house value of around 60,000 dollars of 1982-4. However, the standard deviation on this value is also around 60,000 dollars. These individuals hold, on average, around 12,000 constant dollars of liquid wealth. About $33 \%$ of the individuals have negative liquid wealth, that is, they are in debt for that amount. However, total wealth (net liquid wealth plus the market value of the house) amounts to slightly less than 40,000 dollars. Only $8 \%$ of individuals exhibit negative total wealth. Clearly, owning a home is the only way to support these debts. Around $72 \%$ of individuals are employed, with an average wage of $\$ 4,726$ per quarter, or 8.26 in log-wages.

[Table 3 here]

Table 3 shows summary statistics by homeownership and employment status. Renters hold slightly more liquid assets than owners, $\$ 12,300$ vs $\$ 11,300$. About $61 \%$ of owners and $12 \%$ of renters are in debt, that is, have negative liquid wealth. However, the totality of renters wealth is liquid, whereas homeowners total wealth is around $\$ 71,000$, and only $3 \%$ of them have a negative total wealth position. Out of all renters $52 \%$ are employed, with an average wage of $\$ 3,400$ (7.92 in log-wages), while $78 \%$ of all owners are employed, with an average wage of $\$ 5,100$ (8.35 in log-wages).

Employed individuals are more than twice as likely to be home owners: $47 \%$ of the employed are owners compared to only $21 \%$ of the unemployed. Moreover, the value of the houses owned by the employed is also greater: $\$ 63,000$ compared to $\$ 47,000$ for the unemployed. Similarly, liquid and total wealth of the employed are both greater than that of the unemployed. While the employed have around $\$ 15,000$ worth in liquid wealth and around $\$ 49,000$ of total wealth, the unemployed have, respectively, around $\$ 6,700$ and $\$ 19,000$. However, a larger percentage of the employed, $38 \%$, have negative liquid wealth, compared to $25 \%$ of the unemployed. Because the employed are more likely to be homeowners, they also are more likely to have debts on their house, which explains their negative liquid wealth position.

[Table 4 here]

Table 4 shows the main variables of our model 4, 12, and 20 years after leaving high school. Homeownership increases from $5 \%$ in year 4 to $66 \%$ in year 20 , while the 
value of the house owned increases from around $\$ 31,000$ to $\$ 64,000$ for the same years. Liquid wealth also increases for both renters and homeowners. Log-wages increase from 7.9 in year 4 to 8.5 in year 20, which is an increase of around $60 \%$ over this period. The dispersion of log-wages is relatively stable over time at 0.5. Meanwhile, the unemployment rate declines from $43 \%$ in year 4 to $10 \%$ in year 20 . This is the result of increasing rates for job taking and job-to-job transitions, and decreasing rates for job separations.

These trends are informative of the evolution of the main variables of the model and of their interconnections. They suggest that better labor market outcomes are associated with homeownership, which involves borrowing and, hence, negative holdings of liquid assets. Accordingly, homeowners have typically more total wealth, but less liquid wealth than renters. Our next step is an estimation of the behavioral parameters of the model.

\section{Estimation}

The estimation strategy aims to recover the behavioral parameters of the theoretical model. The estimation procedure is a Simulated Method of Moments (SMM) in which the parameter estimates of the theoretical model are the minimizers of this function. We build a set of simulated data and use it to compute some selected moments that are then matched to the actual moments. For each individual in the sample we generate 100 simulations. Since wealth and housing are observed only since 1985, there are several periods for which we can only observe employment and wage data, but not wealth and housing data. For these periods data for simulations are assumed to be the same than actual data. From the quarter that we first observe wealth onward we use the policy rules that solve the dynamic programming problem and random numbers for the stochastic components (job offers, layoffs, wage offers, and house price fluctuations) to generate simulated career paths. That is, simulated data are based on observed liquid wealth and observed employment status and wages, assuming no homeownership and a medium housing unit price. At each iteration of the parameter computation we construct a measure of distance between the observed and the simulated moments. Since for many quarters there are very few actual observations, we compute biannual periods both in the actual and the simulated moments.

In the estimation, we will only use data for the first 26 years of labor market experience, which approximately contains observations from 1978 until year 2005 for 
most people. That is, we are trimming the sample to cover the period just before the Great Recession. Our purpose is to have an estimation that covers the pre-crisis situation and produce ourselves some changes in the economic environment that are similar to what actually happened.

The parameters to estimate are then $\Theta=\left\{d, a, \mu_{p}, \phi, \sigma_{p}, r_{h}, \rho, \gamma, b, \lambda, \alpha_{\lambda}, \theta\right.$,

$\left.\alpha_{\theta}, \mu, \alpha_{1}, \alpha_{2}, \sigma\right\}$. The moments used in this estimation are the following:

1. percentage of owners by years after graduation,

2. value of the house,

3. liquid wealth holdings by years after graduation and homeownership status,

4. log-wage means and standard deviations by years after graduation, and

5. employment rates and employment transitions by years after graduation.

The SMM procedure relates a parameter set to a weighted measure of distance between sample and simulated moments:

$$
S(\Theta)=\Delta m^{\prime} W^{-1} \Delta m
$$

where $\Delta m=\left(m_{a}-m_{p}\right)$ is the distance between each sample and simulated moment and $W$ is a weight matrix. The estimated behavioral parameters are thus $\widehat{\Theta}=$ $\arg \min S(\Theta)$. We minimize this function by means of the Powell algorithm (Press et al. 1992) which uses direction set methods to find the minimum. This algorithm relies on function evaluations, not gradient methods.

\section{Results}

The estimates and their corresponding asymptotic standard errors are reported in Table 5. As we will show in the next subsections, they are able to reproduce the observed trends in the evolution of homeownership status, house value, liquid wealth by homeownership, wages, unemployment rate and employment transitions.

The share of non-durable consumption is determined by observed liquid wealth and the observed value of the house. The coefficient of risk aversion is pinned down by wealth accumulation over time. The downpayment rate is identified mainly by the process of liquid wealth accumulation required to buy a house. The adjustment 
fee is pinned down by the observed variation in house values. In this estimation the process for housing prices serves as an unobservable and the rent per house unit as an unobserved threshold that makes the estimation feasible. Labor market parameters are identified mainly by observed wages and transitions per quarter, as it is well established in prior estimations. ${ }^{10}$

[Table 5 here]

The downpayment rate is a relatively high 29 percent. The adjustment fee is a realistic $4 \%$ of the variation in house size. The stochastic process for the housing price has an autocorrelation coefficient of 0.65 , which reveals a moderate persistence over time. The mean is -0.033 , which implies an average price slightly below one, as the Markov process is in logarithmic values. The standard deviation for this process is 0.43 , which is relatively high. Given that we work with three house prices, these parameters imply they are: $\mathrm{p}(1)=0.516, \mathrm{p}(2)=0.909, \mathrm{p}(3)=1.600$, and a transition process

$$
P\left(p_{t+1} \mid p_{t}\right)=\left[\begin{array}{lll}
0.448346 & 0.448346 & 0.103308 \\
0.157731 & 0.684538 & 0.157731 \\
0.103308 & 0.448346 & 0.448346
\end{array}\right]
$$

This process implies that in the long run the mean price is 0.96074 . Rent is around $5 \%$ of the average house value. In the absence of data on house prices or rents, these parameters are mainly identified by the observed evolution of home ownership and house values, as well as the observed liquid wealth evolution by home ownership.

The coefficient of risk aversion is 2.06 , which is in the range of prior estimations, and the share of nondurable consumption is $52 \%$, in line with descriptive data. The rate of discount is fixed at 0.9872 and the interest rate at 0.012272 , quarterly values that match annual values of 0.95 and 0.05 , respectively.

The estimated amount of net transfers while unemployed is about $\$ 1,150$. At the beginning of active life, when the agent has no work experience, the probability of receiving an offer $\lambda$ is $9.6 \%$. A growth parameter $\alpha_{\lambda}$ of 0.0172 implies that 20 quarters $(6$ years) after graduation this probability becomes $13 \% ; 40$ quarters (10

\footnotetext{
${ }^{10}$ The identification of behavioral labor market parameters from data on wages and employment transitions is discussed by Flinn and Heckmann (1982a,1982b) and Wolpin (1992). The identification in models of wealth accumulation and job search is discussed by Blundell, Magnac and Meghir (1997) and Rendon (2006).
} 
years) after graduation the probability is $17 \%$, and at quarter 80 (20 years), $30 \%$. While employed the probability of receiving an offer $\pi$ with no experience is $7 \%$. A parameter $\alpha_{\pi}$ of -0.0245 implies that 20 quarters after graduation the arrival rate becomes $4.4 \%$, at quarter $40,2.7 \%$, and at quarter $80,1.1 \%$. The base layoff rate $\theta$ is $39.8 \%$. A parameter $\alpha_{\theta}$ of -0.0255 implies that at quarter 20 after graduation the arrival rate becomes $28.4 \%$, at quarter $40,19.2 \%$, and at quarter $80,7.9 \%$. The estimated base mean of the underlying distribution of log-wages is 7.25 , and the corresponding variance is 0.94. Parameters $\alpha_{1}=0.002271238$ and $\alpha_{2}=-0.000003161$ imply that at quarter 20 after graduation the base mean log-wage offer becomes 7.30, at quarter 40,7.34, an increase of $5 \%$, and at quarter 80, 7.42, an increases of $17 \%$. These parameters imply that wages peak at quarter 359 (around 90 years of age), that is, during active life (188 quarters) wages always go up.

Asymptotic standard errors are calculated using the outer-product gradient estimator and provided in parentheses; they are, in general, small.

To assess whether these parameter estimates capture the essential features of the observed data, we compare the observed and the predicted trajectories of homeownership, house value, wealth by homeownership, wages, employment status, and employment transitions.

[Table 6 here]

[Figures 4 and 5 here]

Table 6 provides a summary of actual and predicted distributions of all variables for years 4, 12, and 20 after graduation. It also shows goodness of fit tests $\chi^{2}$ for discrete variables and $R^{2}$ for continuous variables. ${ }^{11}$ In addition, Figures 4 and 5 present a graphical comparison of actual and predicted variables by year after graduation. Figure 4a shows that the predicted path of the homeownership rate is relatively close to the actual path, which can be confirmed by looking at the $\chi^{2}$ statistics in Table 6 . Figure $4 \mathrm{~b}$ shows that the actual value of the house is very closely replicated

\footnotetext{
${ }^{11}$ For discrete variables we use $\chi^{2}=\Sigma_{t=1}^{T} \frac{\left(n_{t}-\hat{n}_{t}\right)^{2}}{\hat{n}_{t}}$, where $n_{t}$ is the actual number of observations at time $t, \hat{n}_{t}$ is the model predicted counterpart, and $T$ is the number of periods. This statistic has an asymptotic $\chi^{2}$ distribution with $T-1$ degrees of freedom.

For continuous variables we use a $R^{2}$ statistic, defined as $R^{2}=\frac{\sum \widehat{Y}^{2}}{\sum \widehat{Y}^{2}+\sum e^{2}}$, where $\widehat{Y}$ is the predicted continuous variable and $e=Y_{o b s}-\widehat{Y}$ is the predicted error. Squaring and summing across observations, we obtain $\sum Y_{o b s}^{2}=\sum \widehat{Y}^{2}+2 \sum \widehat{Y} e+\sum e^{2}$, and it is not necessarily true that $\sum \widehat{Y} e=0$, as in the linear regression framework.
} 
by the model. Figure 4c compares the actual and predicted liquid wealth of renters. It shows some under-prediction in the earlier years and some over-prediction in the later years. Figure $4 \mathrm{~d}$ shows the actual and predicted liquid wealth of owners. In spite of some noise in the liquid wealth data, the model reproduces quite well the observed trend in wealth accumulation, as $R^{2}$ statistics in Table 6 reassure.

Figure 5 shows the actual and predicted evolution of labor market variables. We can see the predicted path of the unemployment rates is relatively close to the actual path, especially at the beginning of the employment careers, which can be confirmed by looking at the $\chi^{2}$ statistics.

Figures $5 \mathrm{a}$ and $5 \mathrm{~b}$ show that the model reproduces well the wage distribution, especially in the later periods; so do their respective $R^{2}$ statistics in Table 6 . Figure $5 \mathrm{c}$ shows that the model reproduces well the unemployment rate, particularly in early years. After some overprediction in later years, over time the model converges to the actual path, even though there are some fluctuations that the model does not capture. The predicted transitions from unemployment to employment are presented in Figure 5d, which shows also a fairly good replication of the actual paths. Figure 5e shows that the model overpredicts transitions from employment to unemployment, as seems to be the case for job-to-job transitions, as shown in Figure $5 f$.

In short, both graphically and formally the model is fairly successful in replicating the main features of the data.

\section{Regime Changes}

After recovering the underlying parameters of the model and assessing their success in replicating the data, we perform two regime changes and report them in Tables 7 and 8 . These experiments measure the variations in several observables produced by relaxing housing credit conditions and by deteriorating labor market demand.

\section{[Table 7 and Table 8 here]}

The first experiment consists of a loosening of housing credit conditions, such as decreasing the downpayment required to buy a house, $d$, by 15 percentage points, reducing the adjustment fee, $a$, to zero or decreasing the mean of the housing price process, $\mu_{p}$, by 5 percentage points. We are interested in evaluating how these regime changes, one at a time and combined, influence the labor market. 
A reduction in the downpayment increases homeownership rates and wealth of renters, who now have an incentive to save more, and decreases liquid wealth held by homeowners, who can buy larger houses. This variation also increases both wages and unemployment rates, while it deteriorates employment transitions, which is consistent with an increase in the reservation wage. Unemployment rates increase 2.5 percent points 20 years after graduation. That is, easier conditions to access housing credit generate higher unemployment rates.

Reducing to zero the adjustment fee for buying or selling a house initially increases homeownership, but decreases it in later years. Eliminating this friction undermines the need for saving, so agents end up consuming more, which causes wealth of both renters and owners to fall. Meanwhile wages initially become higher, but then fall again. Reservation wages are initially higher, but lower wealth accumulation reduces them in later years. Accordingly, unemployment rates fall over time, and employment transitions improve, that is, transitions from unemployment to employment increase and transitions from employment to unemployment decline.

A fall in the mean of the housing price process increases the rate of homeownership, while increasing wealth of renters and decreasing wealth of owners. This effect is similar to the one produced by lowering the downpayment. The effect on the labor market is an increase in wages and the unemployment rate, which is consistent with increasing reservation wages. Employment transitions also worsen in that the transition from unemployment to employment goes down, while the transition from employment to unemployment increases.

What is the combined effect of all these regime changes? The last column of Table 7 shows the liquid wealth of both renters and owners increases. For renters this combined change implies and incentive to save, while for owners it is an incentive to buy larger houses. In terms of the labor market this change generates a sustained increase of unemployment, up to 6 percent points, while wages increase by at most 9 percentage points. Employment transitions altogether deteriorate: exits from unemployment go down by 3 percentage points, while the job separation rate increases by 1 percentage point. Job-to-job transitions also increase by 0.5 percentage point. In sum, this experiment reveals the type of mechanism underlying the recent Great Recession, which originated in the housing market.

The second experiment consists of deteriorating labor demand, that is, decreasing arrival rates and the base mean wage offer, increasing layoff rates, increasing unemployment transfers, and several combinations of these variations. 
A reduction in base arrival rates while unemployed understandably decreases homeownership rates and liquid wealth holdings of both renters and owners. Average wages fall and unemployment rates increase. Transitions from unemployment to employment decrease, however so do transitions from employment to unemployment. People quit less to search while unemployed, as the value of unemployment has fallen.

An decrease in the mean wage offer produces a similar effect in homeownership rates and wealth of both renters and owners, and it also pushes wages down. However, unemployment rates decline. It is the decrease in reservation wages that makes it possible for wages and unemployment to both fall. Accordingly exits from unemployment increase while job separations and job-to-job transitions do not change much.

Interestingly, an increase in the layoff rate increases homeownership in the later years, while it decreases liquid wealth for both renters and owners. The layoff rate is crucial in determining savings for precautionary reasons. Thus, its increase deteriorates labor market conditions, but it also boosts savings which, ultimately, may be put toward homeownership. As a result of this change, wages fall and unemployment rates increase, while exit from unemployment and job separations both rise, and job-to-job transitions fall.

When all of the previous regime changes happen simultaneously there is a larger fall in homeownership, up to 14 percentage points. Liquid wealth holdings of both renters and owners fall by larger amounts than in any single change (except in initial years for owners), which suggests that because of this labor market deterioration only initially wealthier people buy houses. Over time less initially wealthy people buy houses and their liquid wealth position falls further. This combined change implies an increase in the unemployment rate and a large fall in wages, particularly in the later years (23 percentage points). There is also lower exit from unemployment and less job-to-job transitions, but more job separations.

We also consider the additional impact of an increase in unemployment transfers, which captures the government's attempt to counteract deterioration of labor market conditions, as it is studied by Rothstein (2011) and Hagedorn et al. (2013) Under this combined regime the decline in homeownership rates is also large (12 percent points), but is below what would happen without an increase in unemployment transfers. Wealth of renters also falls by less, but the liquid holdings of owners in the later years decrease by a bit more. Wages fall by 16 percentage points, substantially less than 
the 23 percent points decrease without transfers. Unemployment increases by larger amounts, up to 18 percentage points, mostly due to slower transitions from unemployment to employment. The additional effect of this intervention in unemployment is initially small, 0.3 percentage points, but then it increases to 1.5 percentage points and even to 4 percentage points, in year 20. In sum, this experiment is suggestive of how the Great Recession may have affected the housing market. Once the labor market demand deteriorates, homeownership and liquid wealth holdings fall substantially. A government intervention that increases unemployment transfers is effective in alleviating these effects and avoiding wages to fall further, but it generates larger unemployment rates.

\section{Conclusion}

Typical analysis of the connection between the financial and real sectors focuses on the firm as the relevant economic agent. Firms are constrained in how much they can borrow by how much collateral they have, so that a firm's ability to expand its scale of production depends on how much capital is available to the firm. In this article, we propose an alternative connection between the financial and real sectors by taking the worker as the relevant economic agent. How much a worker can borrow is constrained by the value of his available collateral. The single most important collateral of an individual is his house, so that his ability to reject low wage offers in his job search throughout his active life will be determined by the value of his house. Therefore, easier housing credit conditions allow an individual to be more selective in his job search and obtain higher wages, but they also lengthen the duration of his unemployment spells and, thus, increase overall unemployment rates. We claim that this mechanism may have been at work in producing what has been labelled the Great Recession.

We analyze this phenomenon by means of a model in which agents decide on their job search, savings, homeownership status and house size. Unlike other dynamic models of housing, our framework produces a feed-back effect between housing decisions on the one side and income and unemployment on the other side. That is, the income process in our model is not exogenous; workers decide to accept or reject wage offers and, therefore, have some control over their income. Moreover, we also allow for housing price fluctuations, which affects the borrowing decisions of workers. We also present a 'neutrality' result: in the absence of adjustment fees or downpayment 
requirements, that is, of financial frictions, the liquidity structure of wealth of an individual is irrelevant to his job search decisions and economic activity in general. Only the size of total wealth (value of the house plus liquid wealth) matters.

We fit this model to data from the NLSY and recover the behavioral parameters, which are realistic for both the housing and the labor market. The model exhibits a fairly good capability to replicate the main observables, namely, the evolution of homeownership rates, house value, liquid wealth, wages, and employment status and transitions over time.

We show that more relaxed conditions for borrowing in the housing market increase unemployment rates by around 6 percentage points. We associate this finding with the mechanism underlying the Great Recession, which was preceded by an increase in housing borrowing and saw a substantial increase in unemployment. We also evaluate the effects of a deteriorating labor demand on the housing market. We find that less job creation by employers, captured by lower arrival rates, higher layoff rates and lower wage offers, reduces homeownership by 14 percentage points.

Future research can extend our framework to explore other important dimensions of the connection between housing markets and job search. In our model lenders do not share risk with borrowers, so that they recover their loans with probability one. One could explore how the model's predictions change when a borrower has the option to not pay back his loan, that is, to default. ${ }^{12}$ One could also model the mortgage structure; allow for foreclosures in case of default; consider underwater mortgages; or relax the no-homelessness condition and have some agents become homeless.

In the labor market, an obvious concern is to allow for an equilibrium framework with matching. This will enable the model to assess firms' reaction to relevant regime changes, such as those discussed in the present article. For instance, if workers are more selective in their search, firms will have a harder time finding a worker. Once firms realize this, the value of a vacancy will decrease: firms will open fewer vacancies and the unemployment rate will increase, potentially more so than in a partial analysis.

\footnotetext{
${ }^{12} \mathrm{~A}$ possibility is to declare himself in bankruptcy, which will prevent him from borrowing at all in the future.
} 


\section{Appendix}

\section{A1. Proof or proposition 1}

Proof of Proposition 1 If $a=0$ and $B_{t+1}\left(\chi_{t} H_{t}\right)=c, c \in \mathbb{R}$, then $A_{t}-c\left(H_{t-1}, \chi_{t} H_{t}, p_{t}\right)=$ $A_{t}+p_{t} H_{t-1}-p_{t} H_{t}=Z_{t}-p_{t} H_{t}$.

Without loss of generality, let $V_{T_{F}}^{R}\left(\alpha Z_{t},(1-\alpha) \frac{Z_{t}}{p_{t}}, p_{t}\right)=V_{T_{F}}^{R}\left(Z_{t}, 0, p_{t}\right)$. Then, at the last period of life $T_{F}: V_{T_{F}}^{R}\left(Z_{t}, 0, p_{t}\right)=\max _{\chi_{t}, H_{t}} U\left(Z_{t}+b_{R}-p_{t} \chi_{t} H_{t}-\left(1-\chi_{t}\right) r_{h} H_{t}\right)$, so that only total wealth matters. Then we proceed backward and define the value function

$$
\begin{aligned}
V_{t}^{R}\left(Z_{t}, 0, p_{t}\right)= & \max _{A_{t+1}^{R} \geq 0, \chi_{t}, H_{t}}\left\{U\left(Z_{t}+b_{R}-p_{t} \chi_{t} H_{t}-\left(1-\chi_{t}\right) r_{h} H_{t}-\frac{A_{t+1}}{1+r}, H_{t}\right)\right. \\
& \left.+\beta \int V_{t+1}^{R}\left(Z_{t+1}, 0, p_{t+1}\right) d P\left(p_{t+1} \mid p_{t}\right)\right\} .
\end{aligned}
$$

At period $t$ the agent decides on $A_{t+1}$ and $H_{t}$, with which for any expected price $p_{t+1}$ conditional on price $p_{t}$ he calculates total wealth $Z_{t+1}$. He integrates the value function at $t+1$ and then he computes $V_{t}^{R}\left(Z_{t}, 0, p_{t}\right)$. The process is repeated backwards until the first period of retirement. Then the process is repeated backward throughout the agent's active life

\section{A2. Definition of the variables}

For tractability, we aggregate the data to quarters based on the calendar quarter in which the individual starts his employment history. The last week that the individual reports being enrolled in school is assigned to its corresponding calendar quarter; employment history starts in the quarter thereafter. The relevant time unit is quarters of experience, not calendar time. Along with attrition and missing data, this implies that not all individuals are observed through 2010. Aggregation to quarterly data has the unavoidable consequence of some definitional arbitrariness. We define an individual to be working if he is employed during the first week of the quarter; otherwise he is unemployed for that quarter. The job corresponding to that quarter is also the first job of the quarter; any other job held during the quarter is ignored. The quarterly wage related to that job is the wage of the first week of the quarter in 1982-4 dollars times 13. As the NLSY provides information on multiple jobs held by a person at the same period, the main job is taken to be the one with the most hours of work. A person is given the status of employed if he works 20 or more hours per week. The Consumer Price Index is used to transform the monetary values into real amounts.

The NLSY contains annual data on the financial characteristics of the household, for years 1985 onwards. Respondents report the market value of their assets at the moment of the interview; this information is therefore assigned to its particular calendar quarter, leaving blank all other quarters. There are five types of assets: residential property, financial assets, business assets, vehicles and other; all these components are computed at their "market value" which the NLSY defines as the amount the respondent would reasonably expect someone else to pay if the particular asset were sold today in its present condition. Thus, residential property is the market value of the respondent's house or apartment owned or being bought by the individual. We define as liquid wealth the sum of the other assets net of liabilities. That is, the net value reported for liquid wealth is the sum of financial 
assets, business assets, vehicles, and other assets minus any liability on residential property, such as mortgages, back taxes, home improvement loans, or debts such as assessments, unpaid amounts of home improvement loans, or home repair bills. Since the NLSY reports a variable named "total assets," to construct "liquid wealth," we just subtract the market value of the residential property from this total. 


\section{References}

Acemoglu, D., And R. Shimer (1999): "Efficient Unemployment Insurance," Journal of Political Economy, 107(5), 893-928.

Blanchflower, D. G., And A. J. Oswald (2013): "Does High Home-Ownership Impair the Labor Market?," IZA Discussion Papers 7640, Institute for the Study of Labor (IZA).

Blundell, R., T. Magnac, and C. Meghir (1997): "Savings and Labour Market Transitions," Journal of Business and Economic Statistics, 15(2), 153-164.

Bover, O., J. Muellbauer, And A. Murphy (1989): "Housing, Wages and UK Labour Markets," Oxford Bulletin of Economics and Statistics, 51(2), 97-136.

Burdett, K., And D. Mortensen (1998): "Wage Differentials, Employer Size, and Unemployment," International Economic Review, 39, 257Ü273.

Chambers, M., C. Garriga, and D. Schlagenhauf (2009): "Accounting for Changes in the Homeownership Rate," International Economic Review, 50(3), 677-726.

(2011): "Did Housing Policies Cause the Post-War Boom in Homeownership? A General Equilibrium Analysis," Working Paper No. 2011-01, Towson University, Maryland, revised Feb 2011.

Costain, J. (1999): "Unemployment Insurance with Endogenous Search Intensity and Precautionary Saving," Unpublished manuscript.

DANForth, J. P. (1979): "On the role of consumption and decreasing absolute risk aversion in the theory of job search," in Studies in the Economics of Search, ed. by S. A. Lippman, and J. McCall, pp. 109-131. North-Holland, New York.

Díaz, A., And M. J. Luengo-Prado (2010): "The Wealth Distribution with Durable Goods," International Economic Review, 51(1), $143 \mathrm{U} 170$.

Fisher, J., AND M. Gervais (2011): "Why Has Homeownership Fallen Among the Young?," International Economic Review, 52(3), 883Ü912.

Flatau, P., M. Forbes, P. H. Hendershott, and G. A. Wood (2003): "Homeownership and Unemployment: The Roles of Leverage and Public Housing," NBER Working Paper 10021.

Flavin, M., and S. Nakagawa (2008): "A Model of Housing in the Presence of Adjustment Costs: A Structural Interpretation of Habit Persistence," American Economic Review, 98(1), 474-95.

Flinn, C., And J. Heckman (1982a): "Models for the Analysis of Labor Force Dynamics," Advances in Econometrics 1, pp. 35-95.

(1982b): "New Methods for Analyzing Structural Models of Labor Force Dynamics," Journal of Econometrics, 188, 115-68.

Gervais, M. (2002): "Housing Taxation and Capital Accumulation," Journal of Monetary Economics, 49(7), 1461-1489. 
Green, R., And P. Hendershott (2001): "Homeownership and Unemployment in the US," Urban Studies, 38, 1509-1520.

Hagedorn, M., F. Karahan, I. Manovskit, and K. Mitman (2013): "Unemployment Benefits and Unemployment in the Great Recession: The Role of Macro Effects," NBER Working Papers 19499, National Bureau of Economic Research, Inc.

Haurin, D. R., P. H. Hendershott, and S. M. Wacther (1997): "Borrowing Constraints and the Tenure Choice of Young Households," Journal of Housing Research, $8(2), 137-154$.

Iacoviello, M., And M. Pavan (2013): "Housing and Debt over the Life Cycle and Over the Business Cycle," Journal of Monetary Economics, 60(2), 221-238.

Laufer, S. (2008): "A Life-cycle Approach to Housing with Job Search," Manuscript. New York University.

Lentz, R. (2009): "Optimal Unemployment Insurance in an Estimated Job Search Model with Savings," Review of Economic Dynamics, 12(1), 37-57.

Lise, J. (2013): "On-the-Job Search and Precautionary Savings," Review of Economic Studies, 80(3), 1086-1113.

Mian, A., And A. Sufi (2011): "House Prices, Home Equity-Based Borrowing, and the US Household Leverage Crisis," American Economic Review, 101(5), 2132-56.

Mortensen, D. (1977): "Unemployment Insurance and Job Search Decisions," Industrial and Labor Relations Review, 30, 505-517.

Oswald, A. (1997): "Theory of Homes and Jobs," Mimeo, Warwick University.

Press, W. H., S. A. Teutolsky, W. T. Vetterling, and B. P. Flannery (1992): Numerical Recipes in FORTRAN: The Art of Scientific Computing. Cambridge University Press, New York.

Rendon, S. (2006): "Job Search and Asset Accumulation under Borrowing Constraints," International Economic Review, 47(1), 233-263.

Rothstein, J. (2011): "Unemployment Insurance and Job Search in the Great Recession," Brookings Papers on Economic Activity, 43(2 (Fall)), 143-213.

Sanchez, J. M. (2007): "An Estimable Dynamic Model of Housing Tenure Choice," Unpublished manuscript, Instituto de Economía, Pontificia Universidad Católica de Chile.

Sommer, K., P. Sullivan, and R. Verbrugge (2013): "The Equilibrium Effect of Fundamentals on House Prices and Rents," Journal of Monetary Economics, 60(7), 854870.

Wolpin, K. (1992): "The Determinants of Black-White Differences in Early Employment Careers: Search, Layoffs, Quits, and Endogeneous Wages," Journal of Political Economy, $100,535-560$.

YANG, F. (2009): "Consumption over the Life Cycle: How Different is Housing?" Review of Economic Dynamics, 12(3), 423-443. 
Table 1. Sensitivity analysis. Effect of parameter variations on selected statistics.

Variation of statistics resulting from variations of one parameter at a time.

\begin{tabular}{|c|c|c|c|c|c|c|c|c|c|}
\hline \multirow{2}{*}{\multicolumn{2}{|c|}{$\begin{array}{l}\text { Parameter } \\
\text { Variation }\end{array}$}} & \multirow{2}{*}{$\begin{array}{l}\text { Percent } \\
\text { Owners }\end{array}$} & \multirow{2}{*}{$\begin{array}{l}\text { Wealth } \\
\text { Renters }\end{array}$} & \multirow{2}{*}{$\begin{array}{l}\text { Wealth } \\
\text { Owners }\end{array}$} & \multirow{2}{*}{$\begin{array}{c}\text { Log } \\
\text { Wages }\end{array}$} & \multirow{2}{*}{$\begin{array}{r}\mathrm{U} . \\
\text { Rate\% }\end{array}$} & \multicolumn{3}{|c|}{ Transitions in \% } \\
\hline & & & & & & & $\mathrm{U}->\mathrm{E}$ & $\mathrm{E}->\mathrm{U}$ & $\mathrm{E}->\mathrm{E}^{\prime}$ \\
\hline \multicolumn{10}{|c|}{ Statistics Levels } \\
\hline $\mathrm{Ba}$ & ine & 58.51 & 9616 & -324 & 8.30 & 31.85 & 21.59 & 9.66 & 4.35 \\
\hline \multicolumn{10}{|c|}{ Statistics Variations: } \\
\hline \multicolumn{10}{|c|}{ Housing and Savings Parameters } \\
\hline$d$ & 0.1 & -15.98 & -5646 & -750 & -1.76 & -1.28 & 0.88 & -0.21 & -0.85 \\
\hline$a$ & 0.01 & -3.42 & -2024 & -544 & -0.91 & -0.56 & 0.25 & -0.13 & 0.07 \\
\hline$\phi$ & 0.01 & 1.43 & 1220 & 1140 & 0.59 & 0.23 & -0.12 & 0.03 & -0.02 \\
\hline$\mu_{p}$ & 0.01 & -0.66 & -2912 & -632 & -0.77 & -0.83 & 0.54 & -0.22 & -0.06 \\
\hline$\sigma_{p}$ & 0.01 & 1.51 & -1815 & 253 & -0.55 & -0.73 & 0.45 & -0.22 & -0.02 \\
\hline$r_{h}$ & 0.01 & -5.59 & -3624 & -646 & -4.33 & -1.88 & 1.07 & -0.42 & 0.20 \\
\hline$\rho$ & 0.1 & -2.76 & -2291 & -808 & -1.97 & -1.09 & 0.54 & -0.24 & 0.12 \\
\hline$\gamma$ & 0.1 & -0.94 & -5137 & -2201 & -2.88 & -1.99 & 1.37 & -0.33 & 0.06 \\
\hline \multicolumn{10}{|c|}{ Labor Market Parameters } \\
\hline$b$ & 100 & 1.37 & 789 & 358 & 3.71 & 1.04 & -0.86 & -0.03 & -0.25 \\
\hline$\lambda$ & 0.1 & 8.88 & 9669 & 3680 & 13.79 & -3.72 & 5.74 & 0.74 & -1.04 \\
\hline$\alpha_{\lambda}$ & 0.01 & 6.34 & 5325 & 1581 & 11.08 & -4.03 & 6.45 & 0.82 & -0.53 \\
\hline$\pi$ & 0.1 & 2.48 & 2088 & 1269 & 0.88 & 0.76 & 0.07 & 0.51 & 6.23 \\
\hline$\alpha_{\pi}$ & 0.01 & 0.82 & 429 & 597 & -0.05 & 0.03 & 0.4 & 0.29 & 3.60 \\
\hline$\theta$ & 0.1 & -1.78 & -1726 & -1437 & -3.09 & 4.99 & 1.34 & 3.21 & -1.09 \\
\hline$\alpha_{\theta}$ & 0.01 & -3.66 & -2790 & -1573 & -5.26 & 10.7 & 2.29 & 7.46 & -1.44 \\
\hline$\mu$ & 0.1 & 2.02 & 1530 & 906 & 3.7 & 0.11 & 0 & -0.01 & 0.07 \\
\hline$\alpha_{1}$ & 0.01 & 1.34 & 9758 & 9593 & 61.82 & -3.21 & 2.44 & -0.43 & 1.64 \\
\hline$\sigma$ & 0.1 & 2.67 & 2137 & 1401 & 6.25 & 0.44 & -0.36 & -0.04 & 0.13 \\
\hline
\end{tabular}

Note: Log-wages variations are multiplied times 100, so they are read as percent variations. Money amounts are in dollar of 1982-4. 
Table 2. Summary Statistics

Money amounts are in dollar of 1982-4.

\begin{tabular}{|c|c|c|c|c|c|}
\hline Variable & Obs & Mean & St Dev & Min & $\operatorname{Max}$ \\
\hline Owners & 4228 & 0.3697 & 0.4828 & 0 & 1 \\
\hline Value of the House & 1563 & 59484 & 59800 & 640 & 780950 \\
\hline Liquid Wealth & 3582 & 11888 & 84944 & -402691 & 1526997 \\
\hline \multicolumn{6}{|c|}{ Liquid Wealth Distribution (Obs, \%) } \\
\hline$<0$ & 1,189 & 33.19 & & & \\
\hline$=0$ & 172 & 4.80 & & & \\
\hline$>0$ & 2,221 & 62.00 & & & \\
\hline Total Wealth & 3603 & 37927 & 106262 & -151286 & 1633592 \\
\hline \multicolumn{6}{|c|}{ Total Wealth Distribution (Obs, \%) } \\
\hline$<0$ & 295 & 8.19 & & & \\
\hline$=0$ & 210 & 5.83 & & & \\
\hline$>0$ & 3,098 & 85.98 & & & \\
\hline Employed & 29586 & .7169 & .4505 & 0 & 1 \\
\hline Wages & 21238 & 4726 & 3663 & 25 & 140225 \\
\hline Log Wages & 21238 & 8.260 & .688 & 3.219 & 11.851 \\
\hline
\end{tabular}


Table 3. Summary Statistics by Home ownership and employment status Money amounts are in dollar of 1982-4.

\begin{tabular}{|c|c|c|c|c|}
\hline \multirow[b]{2}{*}{ Variable } & \multicolumn{2}{|c|}{ Home Ownership } & \multicolumn{2}{|c|}{ Employment Status } \\
\hline & Renter & Owner & Unemployed & Employed \\
\hline Owners \% & & & 21.24 & 46.64 \\
\hline Value of the House & & 59484 & 46968 & 62990 \\
\hline Liquid Wealth & 12331 & 11315 & 6738 & 14872 \\
\hline \multicolumn{5}{|c|}{ Liquid Wealth distribution (\%) } \\
\hline$<0$ & 12.09 & 60.46 & 24.89 & 38.01 \\
\hline$=0$ & 8.32 & 0.26 & 8.83 & 2.47 \\
\hline \multirow[t]{2}{*}{$>0$} & 79.59 & 39.28 & 66.29 & 59.52 \\
\hline & 100.00 & 100.00 & 100.00 & 100.00 \\
\hline Total Wealth & 12332 & 70799 & 18833 & 48981 \\
\hline \multicolumn{5}{|c|}{ Total Wealth distribution } \\
\hline$<0$ & 12.09 & 3.13 & 10.67 & 6.75 \\
\hline$=0$ & 8.32 & 2.11 & 9.69 & 3.59 \\
\hline \multirow[t]{2}{*}{$>0$} & 79.59 & 94.75 & 79.64 & 89.66 \\
\hline & 100.00 & 100.00 & 100.00 & 100.00 \\
\hline Employed \% & 52.42 & 78.12 & & \\
\hline Wages & 3393 & 5067 & & 4857 \\
\hline Log Wages & 7.920 & 8.351 & & 8.324 \\
\hline
\end{tabular}


Table 4. Summary statistics by selected Years of Experience Money amounts are in dollar of 1982-4.

\begin{tabular}{lrrr}
\hline \hline & Year 4 & Year 12 & Year 20 \\
\hline \hline Percent Owners & 4.9 & 44.7 & 65.8 \\
Value of the House & 30888 & 41351 & 63743 \\
Wealth Renters & 3352 & 9668 & 17155 \\
Wealth Owners & -11584 & -3372 & 5969 \\
& & & \\
Log-Wages & 7.9 & 8.2 & 8.5 \\
St.Dev. Wages & 0.5 & 0.5 & 0.5 \\
& & & \\
Unemployment Rate & 43.0 & 36.6 & 10.3 \\
Employment Transitions & & & \\
Job taking & 17.2 & 18.4 & 24.3 \\
Job separations & 13.4 & 6.8 & 3.2 \\
Job-to-job & 0.6 & 2.2 & 2.0 \\
\hline \hline
\end{tabular}


Table 5. Parameter Values. Labor Market

Asymptotic Standard Errors in Parentheses

\begin{tabular}{lcrrr}
\hline \hline Parameter & $\widehat{\Theta}$ & Estimate & (Asy. St. Error) \\
\hline \hline & $d$ & 0.284609505 & 0.083125481 \\
Downpayment & $a$ & 0.040310014 & 0.002269941 \\
Adjustment fee & $\phi$ & 0.653427498 & 0.169036759 \\
Housing price auto-correlation & $\mu_{p}$ & -.033113677 & 0.009884211 \\
Annual price growth & $\sigma_{p}$ & 0.428437091 & 0.101664305 \\
St. dev. of housing price & $r_{h}$ & 0.049676449 & 0.009421159 \\
Rent as a percentage of house price & $\gamma$ & 2.055905485 & 0.831431883 \\
Coefficient of relative risk aversion: & $\gamma$ & 0.523306750 & 0.163270225 \\
Share of nondurable consumption & $\rho$ & & \\
& & & \\
Unemployment Transfers: & $b$ & 1150.24 & 443.10 \\
Arrival rate unemployed: base & $\lambda_{0}$ & 0.095954585 & 0.014881129 \\
growth & $\alpha_{\lambda}$ & 0.017276284 & 0.006332185 \\
Arrival rate employed: base & $\pi_{0}$ & 0.070423183 & 0.014843291 \\
growth & $\alpha_{\pi}$ & -.024486336 & 0.001767432 \\
Layoff rate: base & $\theta_{0}$ & 0.397699817 & 0.094332743 \\
growth & $\alpha_{\theta}$ & -.025489462 & 0.000147733 \\
Mean of base logwages: & $\mu$ & 7.253546689 & 1.114667454 \\
growth linear & $\alpha_{1}$ & 0.002271238 & 0.000518375 \\
growth quadratic & $\alpha_{2}$ & -.000003161 & 0.000000433 \\
Standard deviation of logwages & $\sigma$ & 0.936240317 & 0.105837373 \\
\hline \hline
\end{tabular}


Table 6. Summary. Actual and Predicted Choice Distribution (in percent)

All Variables for four selected Years of Experience

Money amounts are in dollar of 1982-4.

\begin{tabular}{lrrrrrrrr}
\hline \hline & \multicolumn{9}{c}{ Years of Experience } & & Fit \\
& \multicolumn{2}{c}{ Year 4} & \multicolumn{2}{c}{ Year 12} & \multicolumn{2}{c}{ Year 20} & $R^{2}$ & $\chi^{2}$ \\
& Act. & Pred. & Act. & Pred. & Act. & Pred. & & \\
\hline \hline & & & & & & & & \\
Percent Owners & 4.9 & 24.8 & 44.7 & 45.9 & 65.8 & 62.6 & & 6.1 \\
Value of the House & 30888 & 28362 & 41351 & 41556 & 63743 & 63103 & 0.9939 & \\
Wealth Renters & 3352 & 986 & 9668 & 3521 & 17155 & 16739 & 0.8463 & \\
Wealth Owners & -11584 & -1828 & -3372 & -1926 & 5969 & 5037 & 0.7544 & \\
& & & & & & & & \\
Log-Wages & 7.9 & 8.1 & 8.2 & 8.2 & 8.5 & 8.4 & 0.9999 & \\
St.Dev.Log-Wages & 0.5 & 0.5 & 0.5 & 0.5 & 0.5 & 0.4 & 0.9870 & \\
& & & & & & & & \\
Unemployment Rate & 43.0 & 45.1 & 36.6 & 40.4 & 10.3 & 26.1 & & 26.8 \\
Employment Transitions & & & & & & & & \\
Job finding & 17.2 & 17.7 & 18.4 & 20.2 & 24.3 & 21.9 & & 11.5 \\
Job separations & 13.4 & 15.8 & 6.8 & 13.1 & 3.2 & 7.4 & & 14.1 \\
Job-to-job & 0.6 & 1.2 & 2.2 & 4.3 & 2.0 & 3.8 & & 5.2 \\
\hline \hline
\end{tabular}

Crit. value at .5 percent signif.: $\chi_{(12)}^{2}=28.3$. 
Table 7. Summary of Regime Change. Effects of Housing Market Loosening on Variation of statistics resulting from Regime Changes.

\begin{tabular}{|c|c|c|c|c|c|c|}
\hline \multirow[b]{2}{*}{ Statistics } & \multirow[b]{2}{*}{$\begin{array}{l}\text { Years } \\
\text { of } \\
\text { Exp. }\end{array}$} & \multirow{2}{*}{$\begin{array}{l}\text { Bench } \\
\text { mark } \\
\text { in } \\
\text { levels }\end{array}$} & \multicolumn{4}{|c|}{ Regime Changes (in variations) } \\
\hline & & & $\begin{array}{c}\text { Down } \\
\text { payment } \\
\Delta d=-0.15\end{array}$ & $\begin{array}{l}\text { Adj. Fee } \\
\Delta a=-a\end{array}$ & $\begin{array}{l}\text { House price } \\
\qquad \mu_{p}= \\
-0.05\end{array}$ & All \\
\hline \multirow[t]{3}{*}{ Percent Owners } & 4 & 24.8 & 7.0 & 2.8 & 2.9 & 9.5 \\
\hline & 12 & 45.9 & 19.5 & 6.4 & 5.2 & 20.7 \\
\hline & 20 & 62.6 & 12.2 & -0.9 & 5.7 & 10.5 \\
\hline \multirow[t]{3}{*}{ Liquid Wealth Renters } & 4 & 986 & -96 & -14 & -36 & -107 \\
\hline & 12 & 3521 & 3549 & -300 & 291 & 6339 \\
\hline & 20 & 16739 & 14168 & -4890 & 3707 & 13853 \\
\hline \multirow[t]{3}{*}{ Liquid Wealth Owners } & 4 & -1828 & -4056 & -491 & 302 & -4993 \\
\hline & 12 & -1926 & -4514 & -991 & -248 & -2564 \\
\hline & 20 & 5037 & -1859 & -2790 & 198 & 1126 \\
\hline \multirow[t]{3}{*}{ Log Wages } & 4 & 809.4 & 1.4 & 0.2 & 0.8 & 1.6 \\
\hline & 12 & 820.4 & 2.6 & 0.1 & 0.3 & 4.4 \\
\hline & 20 & 840.7 & 3.5 & -1.8 & 1.1 & 9.0 \\
\hline \multirow[t]{3}{*}{ Unemployment Rate } & 4 & 45.1 & 0.2 & -0.2 & 0.0 & 0.3 \\
\hline & 12 & 40.4 & 1.2 & -0.1 & -0.1 & 2.7 \\
\hline & 20 & 26.1 & 2.5 & -1.2 & 1.0 & 5.8 \\
\hline \multicolumn{7}{|l|}{ Employment Transitions } \\
\hline \multirow[t]{3}{*}{ Job finding } & 4 & 17.7 & -0.1 & 0.0 & -0.1 & -0.2 \\
\hline & 12 & 20.2 & -0.3 & 0.1 & 0.2 & -1.1 \\
\hline & 20 & 21.9 & -1.6 & 0.4 & -0.8 & -2.7 \\
\hline \multirow{3}{*}{ Job separations } & 4 & 15.8 & 0.0 & 0.0 & 0.0 & 0.1 \\
\hline & 12 & 7.4 & 0.5 & -0.1 & 0.2 & 1.2 \\
\hline & 20 & 7.4 & 0.5 & -0.1 & 0.2 & 1.2 \\
\hline \multirow[t]{3}{*}{ Job-to-job } & 4 & 1.2 & -0.1 & 0.0 & -0.1 & 0.1 \\
\hline & 12 & 4.3 & 1.0 & 0.2 & 0.5 & 1.2 \\
\hline & 20 & 3.8 & 0.4 & 0.5 & 0.4 & 0.5 \\
\hline
\end{tabular}

Note: Log-wages variations are multiplied times 100, so they are read as percent variations. 
Table 8. Summary of Regime Change. Effects of Labor Market Tightening on Variation of statistics resulting from Regime Changes.

\begin{tabular}{|c|c|c|c|c|c|c|c|}
\hline \multirow[b]{2}{*}{ Statistics } & \multirow[b]{2}{*}{$\begin{array}{l}\text { Year } \\
\text { of } \\
\text { Exp. }\end{array}$} & \multirow{2}{*}{$\begin{array}{l}\text { Bench } \\
\text { mark } \\
\text { in } \\
\text { Levels }\end{array}$} & \multicolumn{5}{|c|}{ Regime Changes } \\
\hline & & & $\begin{array}{l}\text { Arrival } \\
\text { rate } \Delta \lambda= \\
\quad-0.05\end{array}$ & $\begin{array}{c}\text { Mean base } \\
\text { wage offer } \\
\Delta \mu=-0.2\end{array}$ & $\begin{array}{c}\text { Layoff } \\
\text { Rate } \\
\Delta \theta=0.05\end{array}$ & All & $\begin{array}{l}\text { All+ } \\
\Delta b / b \\
=0.2\end{array}$ \\
\hline \multirow[t]{3}{*}{ Percent Owners } & 4 & 24.8 & -3.0 & -0.7 & 0.0 & -3.4 & -3.6 \\
\hline & 12 & 45.9 & -11.7 & -3.5 & -0.8 & -14.1 & -14.1 \\
\hline & 20 & 62.6 & -9.8 & -2.2 & 0.7 & -14.0 & -11.9 \\
\hline \multirow[t]{3}{*}{ Wealth Renters } & 4 & 986 & -133 & -26 & -15 & -164 & -163 \\
\hline & 12 & 3521 & -1780 & -704 & -263 & -2078 & -2037 \\
\hline & 20 & 16739 & -8940 & -2948 & -666 & -11205 & -10494 \\
\hline \multirow[t]{3}{*}{ Wealth Owners } & 4 & -1828 & 715 & 192 & 5 & 931 & 986 \\
\hline & 12 & -1926 & -265 & -204 & -273 & -980 & -638 \\
\hline & 20 & 5037 & -3194 & -2046 & -943 & -4175 & -4214 \\
\hline \multirow[t]{3}{*}{ Log Wages } & 4 & 809.4 & -1.8 & -2.0 & -1.2 & -4.8 & -4.1 \\
\hline & 12 & 820.4 & -6.2 & -6.2 & -0.6 & -10.9 & -8.1 \\
\hline & 20 & 840.7 & -16.0 & -6.9 & -1.3 & -23.2 & -15.6 \\
\hline \multirow[t]{3}{*}{ Unemployment Rate } & 4 & 45.1 & 6.4 & -0.2 & 1.7 & 7.9 & 8.2 \\
\hline & 12 & 40.4 & 12.7 & -0.6 & 3.1 & 16.4 & 17.9 \\
\hline & 20 & 26.1 & 5.1 & -0.2 & 2.7 & 7.7 & 11.7 \\
\hline \multicolumn{8}{|c|}{ Employment Transitions } \\
\hline \multirow[t]{3}{*}{ Job finding } & 4 & 17.7 & -6.1 & 0.0 & -0.2 & -6.2 & -6.2 \\
\hline & 12 & 20.2 & -8.1 & 0.5 & 0.6 & -8.0 & -8.5 \\
\hline & 20 & 21.9 & -5.6 & 0.2 & 0.5 & -4.9 & -7.2 \\
\hline \multirow[t]{3}{*}{ Job separations } & 4 & 15.8 & -0.6 & -0.1 & 1.4 & 0.6 & 0.6 \\
\hline & 12 & 7.4 & -0.4 & 0.1 & 1.3 & 0.6 & 0.8 \\
\hline & 20 & 7.4 & -0.4 & 0.1 & 1.3 & 0.6 & 0.8 \\
\hline \multirow[t]{3}{*}{ Job-to-job } & 4 & 1.2 & -0.5 & -0.1 & -0.2 & -0.7 & -0.7 \\
\hline & 12 & 4.3 & 0.1 & 0.0 & -0.4 & -0.7 & -0.9 \\
\hline & 20 & 3.8 & 0.5 & -0.1 & -0.6 & -0.6 & -1.0 \\
\hline
\end{tabular}

Note: Log-wages variations are multiplied times 100, so they are read as percent variations. 


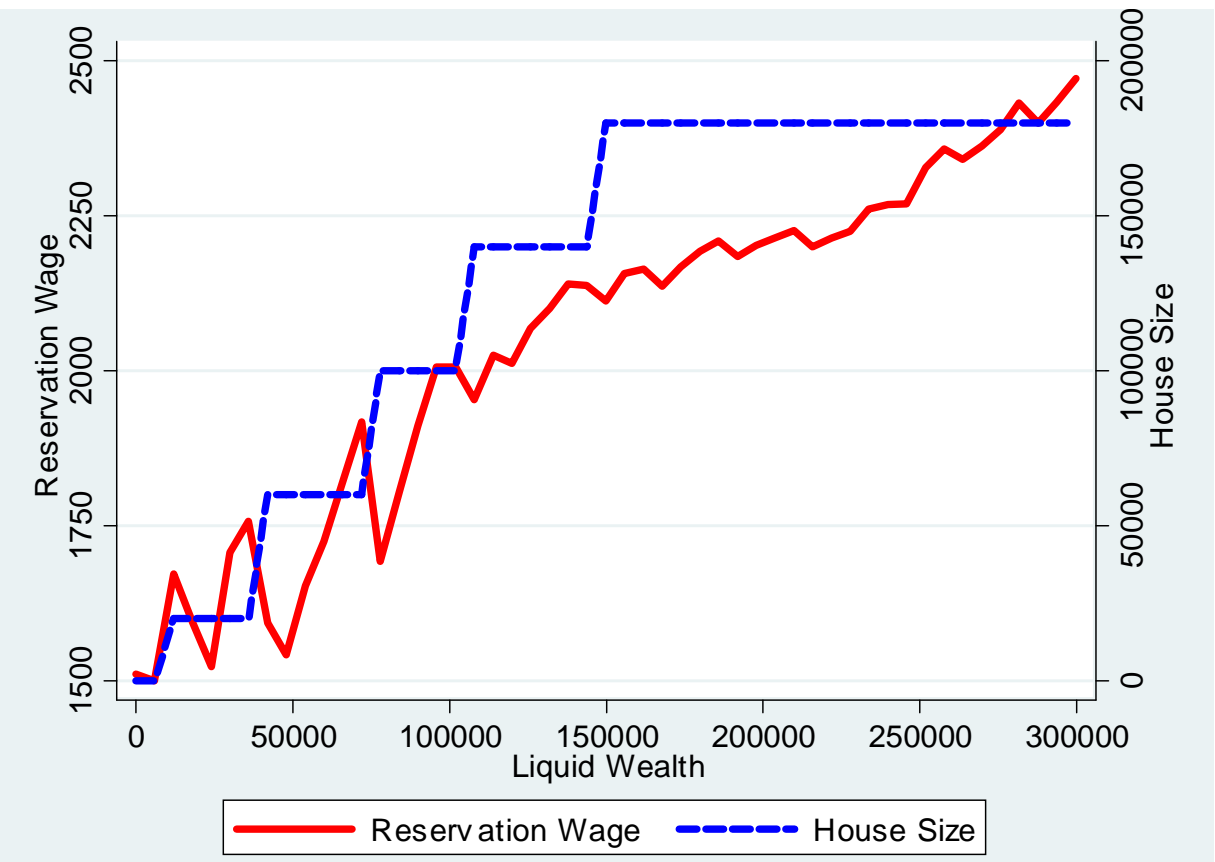

Figure 1. Reservation Wage and House Size as a Function of Liquid Wealth

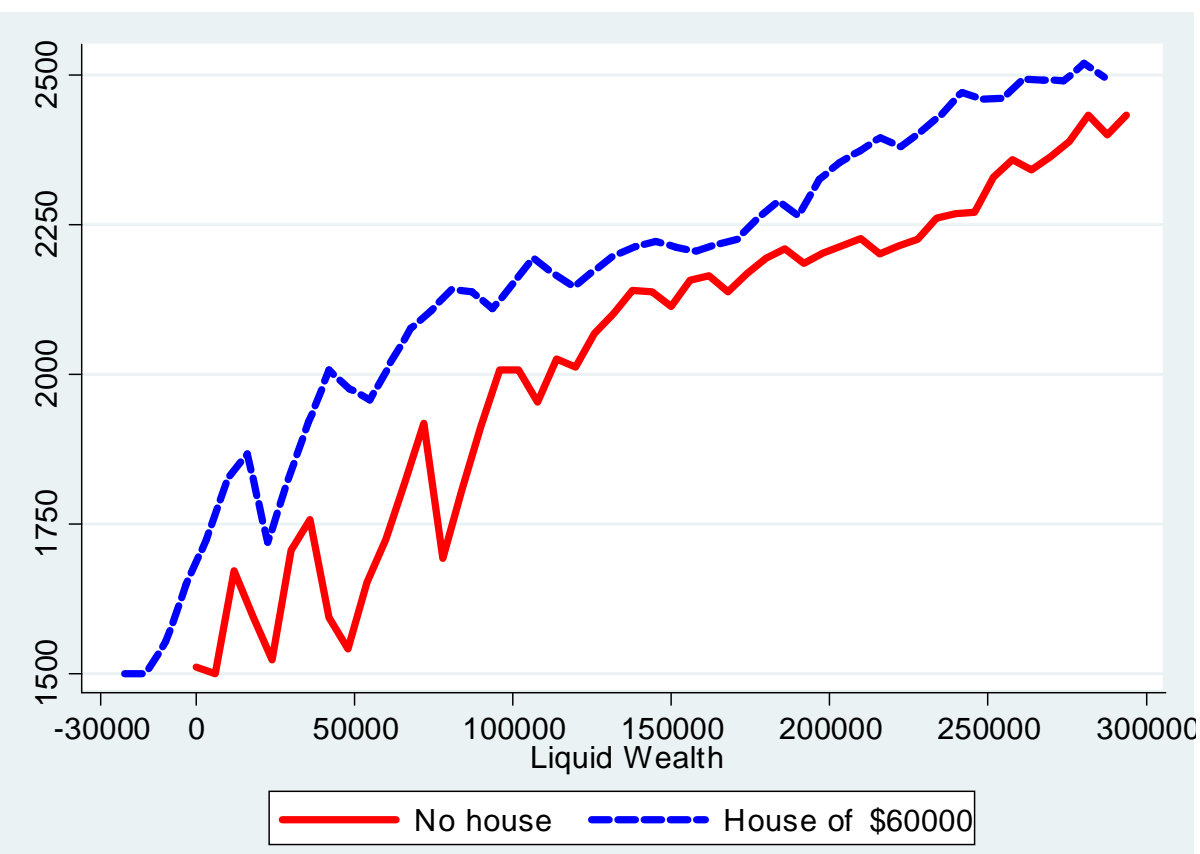

Figure 2. Reservation Wage by Liquidity Wealth Level and House Size 


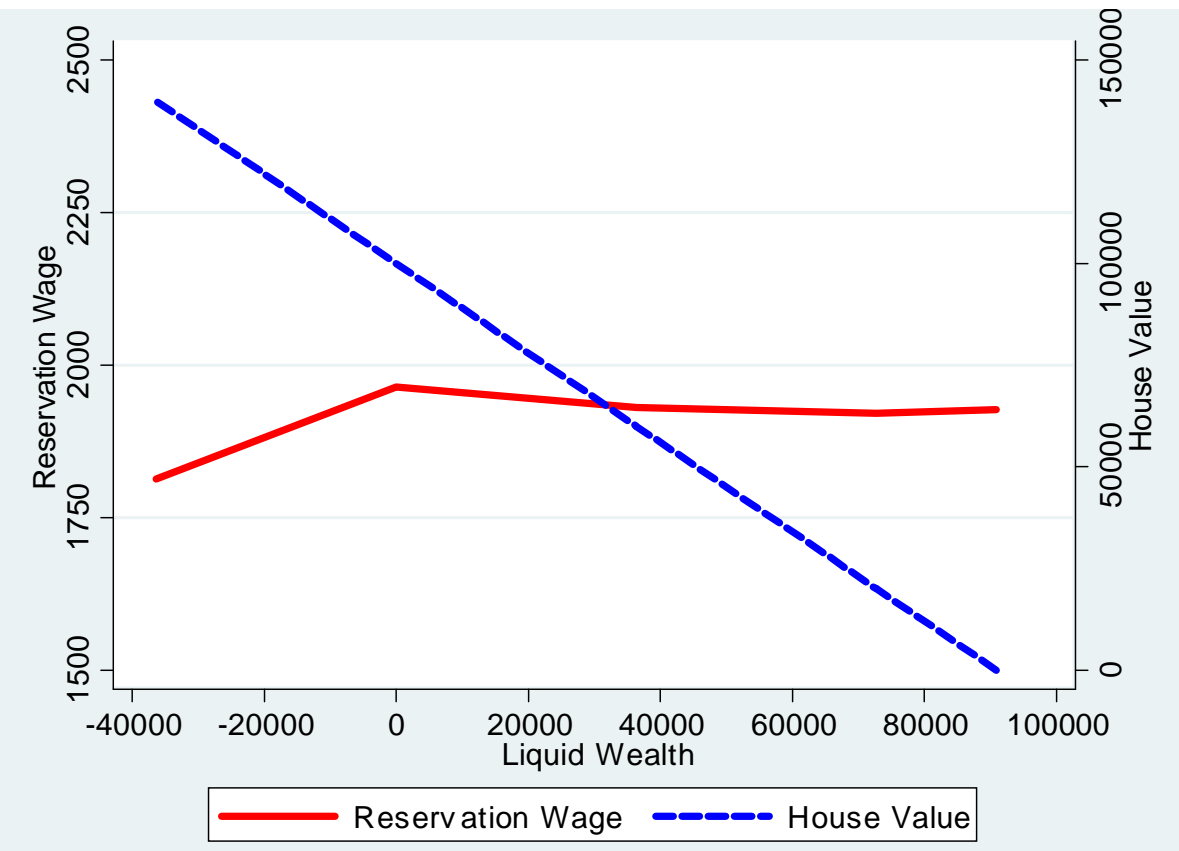

Figure 3. Reservation Wage as a function of Liquid Wealth holding Total Wealth Constant (at \$90882). 

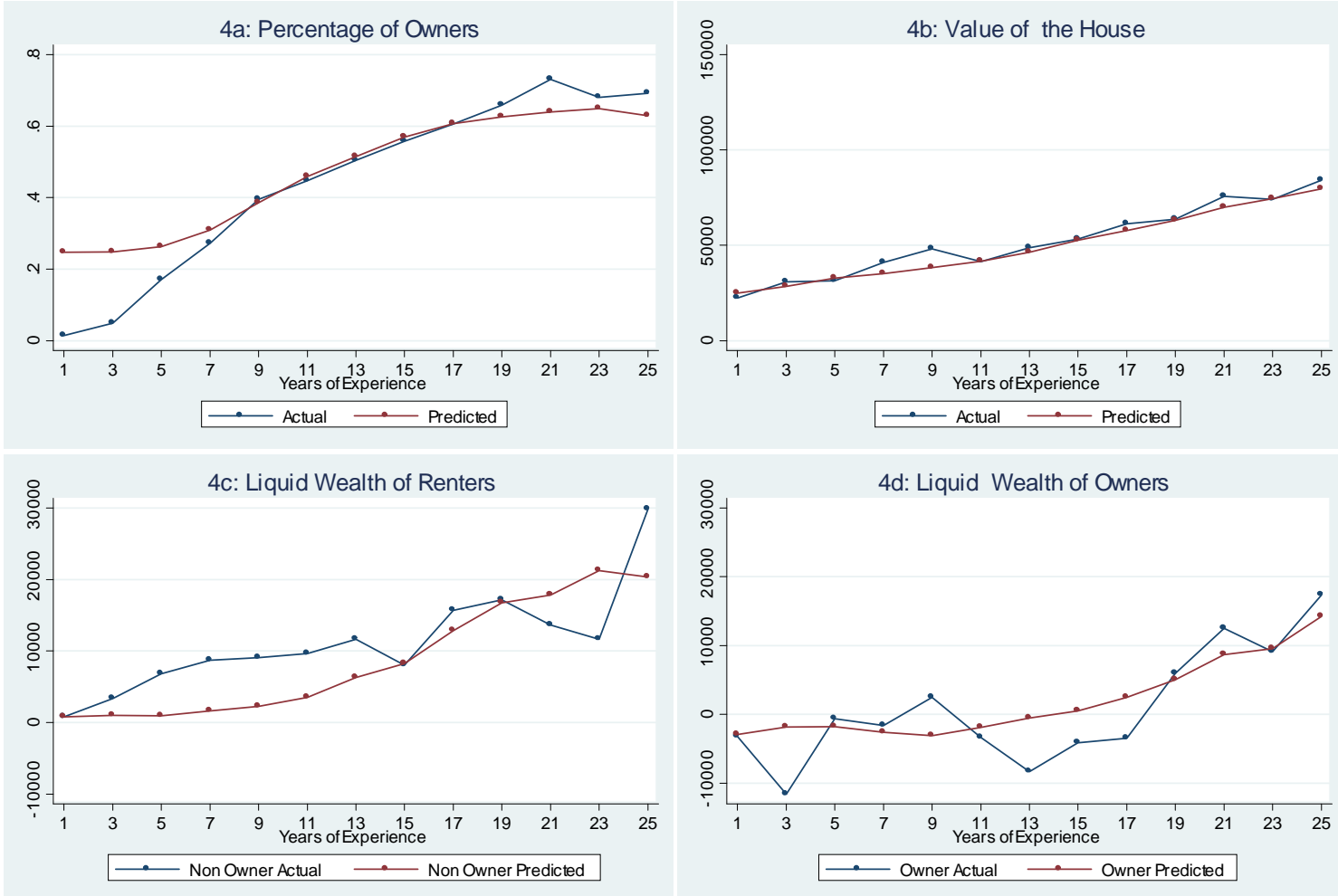

Figure 4: Actual and Predicted Housing Variables 

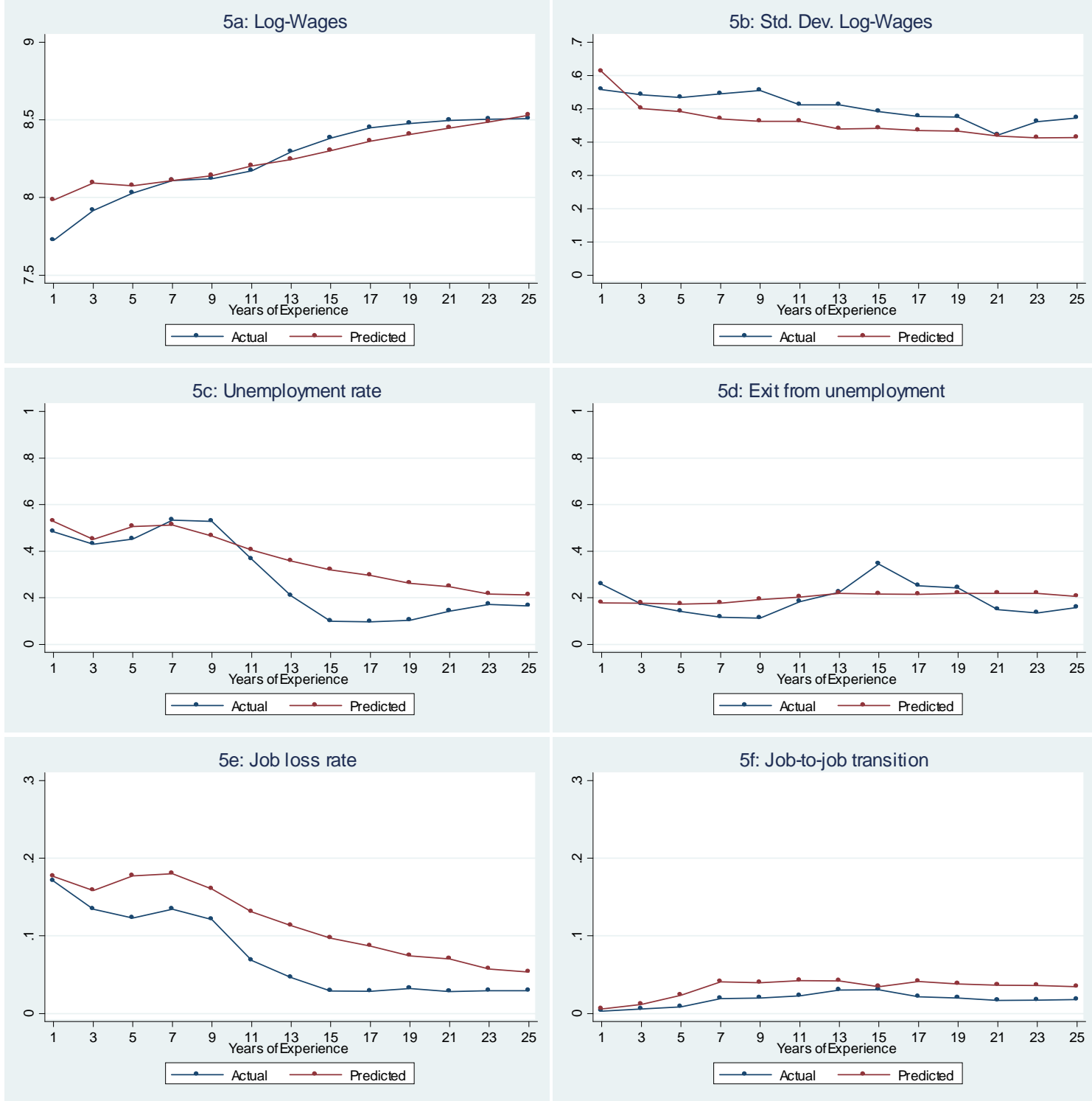

Figure 5: Actual and Predicted Labor Market Variables 